\title{
A PRODUÇÃO DO TURISMO NO CAPITALISMO CONTEMPORÂNEO: O MERCADO DE RESORTS DO MUNICÍPIO DE CONDE (PB)
}

\author{
Rafaella Soares Espinola \\ Maristela Oliveira de Andrade ${ }^{2}$
}

Resumo: O artigo objetiva analisar a produção do turismo de massa sob a lógica
do capitalismo contemporâneo, apresentando as implicações socioambientais desse
modelo no mercado de resorts em expansão na costa de Conde - PB. Adotou-se o
método de abordagem qualitativo, com o auxílio da observação direta e realização
de entrevistas semiestruturadas com representantes do setor público, privado e de
associações comunitárias locais. Concluiu-se que a produção do turismo de massa está
fundamentada na lógica do capitalismo (moderno e contemporâneo), ao obedecer aos
princípios de concentração de riqueza e lucro, e ao dirigir-se para o setor de serviços
com ênfase no consumo, através da imagem e da subjetividade, em detrimento dos
impactos socioambientais. Palavras-chave: Capitalismo contemporâneo, turismo de massa, resorts, impactos socioambientais.

Abstract: The article aims to analyze the production of mass tourism in the logic of contemporary capitalism, presenting environmental implications of this model in the resorts market in expansion on the coast of Conde - PB. We adopted the method of qualitative approach, with the aid of direct observation and semi-structured interviews with representatives from the public, private and local community associations. It was concluded that the production of mass tourism is based on the logic of capitalism (modern and contemporary), when obeying the principles of concentration of wealth and income, and when directing itself for the sector of services with emphasis in the consumption, through the image and the subjectivity, in detriment to the social and environmental impacts.

Keywords: Contemporary capitalism, mass tourism, resorts, social and environmental impacts.

\footnotetext{
${ }^{1}$ Mestre em Desenvolvimento e Meio Ambiente/Prodema (UFPB), Graduada em Turismo (UFPB), Graduada em Relações Internacionais (UEPB). E-mail: rafaellafr@hotmail.com.

2 Professora da Universidade Federal da Paraíba (Prodema e PPGA) Doutora em Antropossociologia das religiões (Univ. Paris III-IHEAL). E-mail: andrademaristela@hotmail.com.
} 
$|122|$

A produção do turismo no capitalismo contemporâneo:...

\section{Introdução}

Compreendendo a atividade turística na complexidade do fenômeno da globalização, fruto da internacionalização financeira e da produção, percebe-se que a produção do turismo seguiu as mesmas tendências econômicas oriundas do sistema capitalista, onde olucroé, geralmente, o principal objetivo, independentemente dos impactos ocasionados nas esferas ambiental, social ou cultural.

Partindo do princípio de que a globalização "dissolve fronteiras, agiliza os mercados, generaliza o consumismo. Provoca a desterritorialização e reterritorialização das coisas, gentes e ideias. Promove o redimensionamento de espaços e tempos" (Ianni, 2002, p.19), no turismo, este fenômeno se traduz como uma singularidade do capitalismo contemporâneo, responsável pela internacionalização do capital, a exigência de mão de obra mais qualificada em alguns setores, a concentração da riqueza nas mãos de uma pequena elite e a frequente exclusão de grande parte das comunidades locais.

O capitalismo contemporâneo resultou do avanço da globalização da economia e evolução das novas tecnologias de informação e comunicação, observadas desde os anos 60. Daí surge uma nova economia política que valoriza o indivíduo como consumidor, as relações de consumo e a dimensão da subjetividade (Costa e Godoy, 2008).

Entretanto, o turismo é uma atividade que engloba simultaneamente elementos de duas formas de capitalismo. Por um lado, do capitalismo moderno com a produção em massa, de forma a reduzir os custos e baratear o produto, onde cada funcionário possui uma função específica, como as atividades operacionais dos hotéis e resorts (seguindo os moldes do modelo fordista). Por outro, do capitalismo contemporâneo com a exigência de mão de obra mais qualificada (que fale inglês, por exemplo) e a preocupação com a especialização dos produtos de acordo com o público-alvo (segmentos do turismo).

$\mathrm{Na}$ atual fase do capitalismo, mais do que vender um produto, vendem-se subjetividades, isto é, valores ideológicos que 
no turismo se traduzem por imagens e valores agregados como o status social. Neste contexto, inserem-se os resorts, símbolos de desenvolvimento para muitos destinos e sinônimo de acumulação capitalista contemporânea. Todavia, há, frequentemente, uma transnacionalização dos resorts, onde o mercado é dominado por grandes redes internacionais que atuam em vários países, mas que destinam os lucros às nações de origem. Na Paraíba, este mercado vem se desenvolvendo de forma tardia, uma vez que o primeiro resort da região (de bandeira angolana) foi inaugurado apenas em 2009. Embora este mercado esteja destinado, a priori, às classes de alto poder aquisitivo, a facilidade das formas de pagamento pelo sistema financeiro e atuais campanhas de marketing através das compras coletivas, inserem os resorts no contexto de turismo de massa, na medida em que estes grandes empreendimentos estão interessados em atrair cada vez mais turistas pautados na ideia de vender o "paraíso" merecido nas férias. Se antes a ideia era focar em um tipo de público, na atual lógica capitalista, permeia o objetivo de não desperdiçar nenhum quarto disponível e oferecer redes de resorts com características relativamente padronizadas.

Para compreender esta lógica, o artigo objetiva analisar a produção do turismo de massa na lógica do capitalismo contemporâneo, apresentando as implicações socioambientais desse modelo no mercado de resorts, e particularmente, nos municípios litorâneos como o Conde, na Paraíba.

Como procedimentos metodológicos, adotou-se o método de abordagem qualitativo, com o auxílio da revisão bibliográfica, observação direta e realização de entrevistas semiestruturadas com 7 líderes comunitários do município de Conde. Foram entrevistados os representantes das seguintes associações: Associação Comunitária de Pesca de Jacumã, Colônia dos Pescadores de Jacumã, Associação dos Agricultores de Tambaba, Assentamento Dona Antônia de Tabatinga, Associação dos Moradores e Amigos de Tabatinga, Comunidade quilombola do Gurugi e Comunidade quilombola de Ipiranga. 
$|124|$

A produção do turismo no capitalismo contemporâneo:...

\title{
Consumindo o lazer: uma crítica ao modelo do turismo de massa
}

O conceito de turismo de massa aqui descrito está associado a uma grande quantidade de pessoas que escolhem destinos turísticos tradicionais (sole mar frequentemente) com características padronizadas, onde o turista compra determinado pacote e se dispõe a usufruir exclusivamente do que foi programado. Neste sentido, de acordo com Cruz (2001, p. 6):

\begin{abstract}
É preciso reconhecer que o "turismo de massa" não significa "turismo das massas" pelo simples fato de que as massas não fazem turismo. $\mathrm{O}$ turismo de massa é uma forma de organização do turismo que envolve o agenciamento da atividade bem como a interligação entre agenciamento, transporte e hospedagem, de modo a proporcionar o barateamento dos custos da viagem e permitir, consequentemente, que um grande número de pessoas viaje.
\end{abstract}

No contexto da globalização, o turismo de massa, difundido no pós-guerra, foi responsável pelo enorme fluxo de pessoas em todo o mundo. Com o surgimento da sociedade urbana industrial, e posteriormente com a institucionalização das férias remuneradas, o tempo não produtivo ou de ócio foi se destinando progressivamente ao lazer e às viagens, como uma forma dos trabalhadores se ausentarem da realidade estressante da rotina de trabalho assalariada do sistema capitalista. As férias remuneradas, assim como o desenvolvimento de tecnologias de transporte, permitiram uma maior democratização do turismo e um fluxo maior de informações e pessoas. Alguns autores sugerem que o turismo de massa iniciou-se na Inglaterra durante a revolução industrial com "a ascensão da classe média e o advento de meios de transporte relativamente baratos" (Theobald, 2001, p. 27).

O tempo livre passou a estar bastante associado ao tempo de consumo nas sociedades pós-modernas, pois este tempo livre remunerado adquirido pela classe trabalhadora dos movimentos sindicais, desde o século XIX, se converteu progressivamente "em 
ato consumista dos espaços de comércio, de serviços e de lazer, de forma cada vez mais acrítica e cada vez mais intensa" (Rodriguez, 1999a, p. 8).

Na esfera econômica, o turismo seguiu mercadologicamente os mesmos princípios de qualquer atividade econômica do capitalismo, onde o importante é consumir. É quase como um círculo vicioso onde se trabalha para produzir e incentivar o consumo e onde se descansa consumindo e gerando trabalho para outras pessoas, isto quer dizer que estamos sempre consumindo, seja uma passagem aérea, um quarto de hotel, um passeio de barco, uma apresentação artística, um bilhete de cinema, etc. (Carlos, 2002).

Os turistas deste modelo globalizante são chamados de psicocêntricos e, geralmente, "são motivados por campanhas publicitárias" (Ignarra, 2003, p. 18). Esse tipo de turista busca destinos padronizados onde se sintam seguros e familiarizados, isto é, viajam sempre nos mesmos ônibus, mesmas cabines de avião, mesmos hotéis climatizados com semelhantes cafés da manhã com o intuito de reconhecer paisagens pré-concebidas e divulgadas pela mídia especializada (revistas, folders, etc.).

Seguindoestemodelo, o turista nãoélivre para estabelecer seu itinerário e seu tempo, pois são guiados por agências especializadas que controlam todos seus passos e horários, fazendo da viagem um momento tão estressante quanto sua rotina de trabalho. Isto acontece nos pacotes turísticos que programam e controlam o tempo e espaço do turista, que acaba ignorando "a identidade do lugar, sua história, cultura, modo de vida" e produzindo "a não relação, o não conhecimento, o distanciamento dado pelo olhar orientado e vigiado que predetermina, preconcebe" (Carlos, 2002, p. 28).

Desta forma, "o sentido de conhecer um lugar se transforma ou se realiza no testemunho da compra: as camisas e as blusas do Hard Rock Café espalhadas pelo mundo, as inúmeras camisetas, bolsas, chaveiros, etc., estampando o nome de lugares sedutores" (Carlos, 2002, p. 30). No caso dos resorts, este distanciamento entre o turista e o lugar é ainda mais evidente transformando os souvenirs 
- comprados, geralmente, dentro dos próprios estabelecimentos - as únicas provas de visita a um determinado local. Com a globalização, estes objetos tornaram-se homogeneizados, podendo ser encontrados em qualquer lugar do mundo, mudando apenas o nome do destino. Contudo, os turistas ainda sentem a necessidade de acumular testemunhos de compras (souvenirs) para provar que vivenciaram um lugar (Augé, 1998a).

Para Carlos (2002, p. 25) o processo de comercialização da cultura, por exemplo, provoca "um sentimento de estranhamento" para os atores locais e ao mesmo tempo transforma tudo em espetáculo onde o turista é apenas um espectador passivo que contempla "cenários ilusórios, vigiados, controlados". Com tais características, os destinos turísticos se tornam padronizados, criando falsas realidades, fantasias, que muitas vezes não correspondem à identidade local. (Ycarim, 2001; Gastal, 2003).

Partindo desse pressuposto, os espaços turísticos, com tais características, seriam como não-lugares, espaços vazios ou falsos lugares, se opondo a noção sociológica de "lugar", isto é, à ideia de uma cultura localizada no tempo e no espaço (Augé, 1998b):

O não lugar é o espaço dos outros sem a presença dos outros, o espaço constituído em espetáculo, o próprio espetáculo já apreendido nas palavras e nos estereótipos que comentam de antemão na linguagem convencionada do folclore, do pitoresco ou da erudição (Augé, 1998b, p. 45).

$\mathrm{Na}$ concepção de Carlos (2002, p.3), os não lugares produzem, na atividade turística, simulacros de lugares através da não identidade assim como "comportamentos e modos de apropriação" destes lugares. Tal comportamento se caracteriza pela não relação e distanciamento do turista com a realidade e comunidade receptora local.

Muitas críticas são apontadas a este modelo que valoriza a espetacularização da cultura e banalização da autenticidade. Luchiari (2000), por exemplo, lembra que este modelo segue 
a lógica da descoberta, exploração e destruição, onde a descoberta é, geralmente, feita pelas elites e aventureiros e as duas últimas etapas são conferidas ao turismo de massa.

Desta forma, o turismo de massa segue as mesmas regras do mercado e racionalidade capitalista, onde transporte, cultura, tudo vira mercadoria. Aliado a isto, fragmentam-se os lugares, afastando o turista do que é feio e pobre. Por estas razões, este modelo promove um desenvolvimento excludente e promotor de desigualdades e contradições sócio-espaciais, chegando a reforçar a hierarquia social por meios de espaços diferenciados, fechados, exclusivos para os turistas (Carlos, 2002) como é o caso dos resorts.

\section{A urbanização turística e a segregação espacial}

O espaço se transforma em mercadoria, de um lado pela mercantilização e ressignificação do valor de uso do espaço para o turismo, e de outro pela produção artificializada do espaço para o usufruto exclusivo do lazer (Carlos, 2002; LuchiarI, 2000). A chamada mercadoria-paisagem "é socialmente produzida como a matéria-prima do turismo" e é responsável pela mercantilização da natureza às manifestações culturais (Ouriques, 2005, p. 49).

Aliado a isto, a modernização dos espaços litorâneos imposta pelo turismo de massa é parcial e superficial, porque ela é "social e espacialmente restrita" (Cruz, 2002, p. 147), limitando-se a poucos territórios e a uma camada específica da sociedade. Neste sentido, a urbanização movida e patrocinada pelo turismo, pode ser positiva para uma localidade, mas concomitantemente prejudicial quando se cria espaços alienados de seus contextos através de "bolhas" turísticas que aumentam a segregação espacial e a exclusão das comunidades autóctones do processo, como é o caso dos resorts que se situam afastados/isolados da realidade local.

Esse modelo de urbanização busca padronizar os complexos turísticos implantados no litoral do Nordeste e reordenar os espaços destinados ao turismo, que, muitas vezes, elitiza as vias costeiras com a ocupação dos espaços por grandes empreendimentos, de 
| 128 |

A produção do turismo no capitalismo contemporâneo:...

alto valor de mercado, e marginaliza a população litorânea local que é, frequentemente, deslocada para outros ambientes por se renderem a especulação imobiliária. Neste caso, "altera-se tanto a "paisagem" física como as relações sociais dos moradores da área que passam a gravitar em torno da indústria e da prestação de serviços" (Rodrigues, 1999, p. 57), pois o turismo traz consigo oportunidades econômicas que modificam o comportamento e costumes locais; um exemplo disso é a inserção dessa população nos empregos de baixa qualificação, que podem representar atividades complementares de renda ou até mesmo substituir as atividades econômicas tradicionais do destino.

Alguns autores chegam até mesmo a classificar esse modelo de urbanização turística como apartheid urbano, no sentido de que o reordenamento do território para fins turísticos promove uma divisão social do território onde as áreas centrais/costeiras são destinadas aos turistas e a população de alto poder aquisitivo, enquanto que as demais áreas são marginalizadas, muitas vezes, abandonadas ou transformadas em favelas que entornam os cartões postais das cidades. Áreas que são maquiadas e escondidas da paisagem turística por não combinarem com os valores estéticos e padrões de consumo do turismo global (Lopes Júnior, 1997).

Mendonça (1999, p. 21) lembra ainda que a paisagem se deteriora de diversas maneiras com a chegada do turismo, e no caso dos resorts, "a transformação dos espaços naturais para implementação de edificações é uma delas". A paisagem é alterada, muitas vezes, de modo negativo ou contrastando com a realidade local, se tornando privatizada e "muitas vezes, inacessíveis aos transeuntes em geral". Algumas vezes não existe se quer um saneamento básico que acompanhe o crescimento desses empreendimentos, ou eles são fornecidos unicamente nas proximidades dos resorts, se tornando uma bolha de consumo privada e um fetiche de paisagem que mascara a identidade e problemas locais. Tais impactos se agravam em períodos de alta temporada, com o aumento do lixo e quando "os despejos de fossas e esgotos acabam contaminando as praias, comprometendo a balneabilidade de suas águas" (Mendonça, 1999, p. 22). 


\section{Implicações socioambientais do capitalismo contemporâneo no mercado de resorts}

Deacordocom Rodrigues(1999,p.31)osresortscorrespondem a "modelos de alojamentos produzidos pelo turismo global, em que as pessoas desfrutam de ambientes absolutamente familiares, onde até, e, sobretudo, a alimentação é estandardizada", ou seja, estes empreendimentos incorporam a tendência da globalização já discutida anteriormente: "um bufê de café da manhã, em qualquer hotel cinco estelas, das megacadeias hoteleiras mundiais, é exatamente igual em Miami, Bangcoc ou Cancún. Afirma-se, sem exagero que o espaço foi desterritorializado". (Rodrigues, 1999, p. 31). E por tais motivos estes empreendimentos se enquadram perfeitamente na categoria de "não lugar" de Marc Augé (1998b).

Os resorts funcionam como "ilhas de prosperidade, criando um circuito privilegiado de consumo e produção" (Ouriques 2005, p.95) que reúne no mesmo lugar uma variedade de produtos e serviços para que o turista não necessite deslocar-se de suas instalações internas em busca de atrativos ou entretenimento, mesmo porque tais empreendimentos estão, frequentemente, conectados com espaços externos - praias, lagos e montanhas, etc. que fazem parte do conjunto arquitetônico que o turista paga para usufruir e tem o privilégio de contemplar por fazer parte do pacote (Ouriques, 2005). Aliás, a estrutura requintada e padronizada dos resorts e sua localização privilegiada não são frutos do acaso, mas obedecem "a uma lógica racional de acumulação capitalista" (Cordeiro et al., 2011, p. 362).

A maior concentração de resorts no Brasil encontra-se no Nordeste, devido às características do clima e paisagem, vista por muitos turistas, sobretudo estrangeiros, como "paraíso tropical". Limonad (2007, p.4) explica que "a crescente inserção do Brasil no turismo internacional contribuiu para acelerar a ocupação e adensamento de locais na costa antes isolados e quase intocados", que criam "territórios turísticos isolados do contexto em que se inserem" (Silva e Vieira Filho, 2009, p. 12). 
$|130|$

A produção do turismo no capitalismo contemporâneo:...

Tais empreendimentos suscitam muitas críticas pelos impactos sociais que causam nas comunidades locais ${ }^{3}$, como a segregação espacial das classes sociais e a exclusão social, uma vez que este tipo de turista, geralmente, não se relaciona com a comunidade local, é privilegiado por praias e áreas privatizadas, não deixa recursos para o comércio local e não traz muitos empregos, já que exigem mão de obra mais qualificada, geralmente, proveniente de fora. Segundo Vieira Filho (2009, p. 5):

Os resorts muitas vezes se encontram desvinculados do entorno e da comunidade (Nicolettit, 2003, p. 62), não geram renda nem emprego, não valorizam a cultura local como um atrativo turístico ou contribuem de alguma forma para a melhoria da qualidade de vida da população local. Esses empreendimentos são alvos de inúmeras críticas pelo fato de satisfazerem todas as necessidades dos turistas, o que reduz consideravelmente a oportunidade de os comerciantes locais beneficiarem-se com a presença dos turistas, que poderiam adquirir souvenirs e utilizar os serviços locais, como restaurantes, lanchonetes e táxis.

Krippendorf (2000, p. 56) utiliza a expressão "férias em guetos" para designar formas artificiais, construídas sob medida, para o descanso e lazer. Esta categoria compreende todos os novos complexos hoteleiros, as cidades, parques e loteamentos de férias "que não nasceram do desenvolvimento de uma aldeia, e que estão situados bem no meio de um prado nos Alpes ou a beira sabe-se lá de que bela praia". O autor concorda com o fato de que os turistas não sentem necessidade de sair desses espaços, citando

\footnotetext{
${ }^{3} \mathrm{O}$ conceito de comunidade suscita muitas controvérsias na antropologia contemporânea, uma vez que a noção clássica proposta por Buber (2008, p. 50) como "a ligação que se desenvolveu mantida internamente por propriedade comum (sobretudo de terra), por trabalho comum, costumes comuns, fé comum"; supõe critérios rígidos como uma unidade fechada e coesa. Contudo, deve-se considerar que as comunidades são permeáveis a influências externas.
} 
o Club Méditerranée como "a versão mais perfeita do turismo em guetos" (Krippendorf, 2000, p. 57). Embora ele acredite que este tipo de turismo seja talvez "a maneira de viajar que produza menos efeitos negativos sobre o país visitado e a população local" (Krippendorf, 2000, p. 57) pelo pouco contato entre o turista e a comunidade, o autor apresenta algumas críticas ao modelo, como o fato desses resorts trazerem pouco impacto econômico para economia local, por importarem quase tudo (da comida aos funcionários) e provocarem o sentimento de exploração por parte da comunidade receptora que utilizando sua expressão "tem que se contentar com migalhas" (Krippendorf, 2000, p. 59). Tais empreendimentos se apropriam do território e provocam o sentimento de exclusão social, e contrariamente ao que propõe este autor, os resorts geram impactos ambientais através da quantidade significativa de recursos naturais que utilizam (água, energia etc.) e os resíduos que produzem. Desta maneira, podem constituir uma forma acintosa de turismo que desdenha a comunidade local e se apresenta numa posição de superioridade ao impor um espaço privativo. Ele é reservado para os que desejam apenas desfrutar da paisagem e temperatura locais, chegando a ser classificado por alguns autores mais críticos como uma forma de neocolonialismo.

Os resorts produzem no espaço globalizado, um lugar que nega seu entorno, constituindo-se, portanto, em um não lugar. Contudo, para os gestores públicos, em geral, os resorts são sinônimos de modernidade e de desenvolvimento, predominando sempre o discurso dos benefícios econômicos para a comunidade por meio do emprego e aumento da renda. E, mais ainda, como um grande estímulo ao turismo internacional no modelo globalizante, que demanda empreendimentos turísticos modernos e de alto padrão internacional. 
| 132 |

A produção do turismo no capitalismo contemporâneo:...

Implicações socioambientais na construção de um mercado de resorts no município de Conde (PB)

O município de Conde possui $172,949 \mathrm{~km}^{2}$ e situa-se a 16,9 km da capital da Paraíba, João Pessoa. De acordo com o IBGE, através do censo demográfico de 2010, o Conde possui uma população de aproximadamente 21.400 habitantes. O turismo é a principal e mais lucrativa atividade econômica do município em razão da extensa $(19,85 \mathrm{~km} 2)$ orla marítima do distrito de Jacumã que concentra as 8 praias do município: Barra de Gramame, Praia do Amor, Jacumã, Carapibus, Tabatinga, Coqueirinho, Tambaba e Praia Bela ( PREFEITURA DE CONDE, 2012).

O grande potencial turístico da região (diversidade de ecossistemas e praias quase desertas) provocou um acelerado crescimento dos equipamentos turísticos sem o acompanhamento proporcional $\mathrm{da}$ infraestrutura de apoio procedente do poder público, o que tem ocasionado uma série de impactos socioambientais negativos tais como o acúmulo de lixo, a poluição visual e sonora, entre outros.

As políticas públicas de turismo do município estão voltadas essencialmente para o segmento "sol e mar", embora existam outras potencialidades a serem melhor trabalhadas como o turismo rural e o ecoturismo, como modelos que provocam menos impactos. A particularidade em relação às outras cidades litorâneas reside no fato de que o município possui características ainda bastante rurais, contando inclusive com diversas comunidades de perfil tradicional situadas em espaços mais distantes das praias entre as quais: assentamentos rurais, comunidades de pescadores artesanais e comunidades quilombolas. Além disso, destaca-se o problema da falta de sistema público de esgotamento sanitário e tratamento de água, sendo o sistema de fossa séptica e poço os mais utilizados.

Outra particularidade consiste no crescente interesse de investidores estrangeiros na região, traduzida pela presença de diversos empreendimentos turísticos de proprietários estrangeiros, fruto de uma forte política de marketing 
internacional desenvolvida pela prefeitura municipal. Desta forma, com base no inventário dos empreendimentos turísticos do município realizado por Guedes (2005) e informações da prefeitura municipal em 2012, dos 47 meios de hospedagem do destino, ao menos 13 eram de proprietários estrangeiros de diferentes nacionalidades (portuguesa, inglesa, angolana, sueca, etc.). Entretanto, a maioria recebe mais turistas brasileiros do que estrangeiros.

Diante deste contexto, surgiu o primeiro resort da região, em 2009, de um grupo angolano, um segundo está em fase de construção (vizinho ao primeiro) e um terceiro projeto com proporções gigantescas tem sido discutido para se instalar na APA da praia de Tambaba. Estes empreendimentos estão marcando uma nova fase do turismo na região, influenciada pela urbanização turística globalizada e que justifica o desenvolvimento da região através dos grandes empreendimentos e investimentos, sobretudo, estrangeiros.

O resort em funcionamento próximo a praia de Tabatinga e o segundo empreendimento em processo de construção também estão localizados dentro da APA de Tambaba, que foi decretada Área de Proteção Ambiental através do Decreto Estadual nº 22.832 / 2002, abrangendo uma área de aproximadamente 3.270 hectares e ampliada, em agosto de 2005, para 11.320 hectares, através do Decreto 26.296 (Brito, 2010, p. 9). A diferença é que as áreas dos dois primeiros resorts são relativamente pequenas $\left(10.000 \mathrm{~m}^{2}\right.$ e $\left.24.500,00 \mathrm{~m}^{2}\right)$, não se situam a beira mar e antes das instalações já eram consideradas antropizadas.

Por outro lado, o terceiro megaprojeto turístico em questão suscita grande polêmica, por estar situado na área costeira, tendo como pré-requisito o desmatamento de uma área de aproximadamente 190 hectares, que vem ocasionando um incipiente conflito socioambiental, expressados em movimentos comunitários contrários ao empreendimento, como um abaixoassinado realizado três anos atrás pela Associação Tambaba Nua (naturista e ambientalista). 
$|134|$

A produção do turismo no capitalismo contemporâneo:...

Na audiência pública, realizada em 14 de janeiro de 2013, para apresentação do relatório de impacto ambiental (RIMA) do empreendimento, a reação da comunidade consultada foi, na sua quase totalidade, contrária a instalação. A participação se deu através de perguntas e debates calorosos com os representantes públicos e do empreendimento em questão. Na ocasião, uma técnica contratada pela empresa que realizou o estudo de impacto ambiental (EIA), obrigatório por lei, apresentou as características do complexo turístico relatando superficialmente os 120 impactos positivos e 115 impactos negativos identificados pela empresa, dos quais a maioria dos negativos não foi considerada grave. A maior ênfase foi dada, obviamente, aos impactos positivos, entre eles: a geração de empregos diretos (382) e indiretos, o aumento do poder de compra da população, o aumento do dinheiro circulante, o aumento na arrecadação de impostos, a valorização imobiliária no entorno e o crescimento do turismo.

Em relação aos impactos negativos foram citados o aumento do tráfego de veículos, a geração de poeiras, a supressão da vegetação, o afugentamento da fauna e o risco de contaminação dos recursos hídricos. Este último item gerou grande repercussão na comunidade presente, que se mostrou indignada com a possibilidade de lançamento de dejetos no rio depois de um suposto tratamento adequado. Muitos líderes comunitários enfatizaram a lógica capitalista presente nestes empreendimentos, se mostrando favoráveis a outros modelos de turismo na região, de menor porte e mais sustentáveis, como a sugestão de chalés ecológicos apresentada pelo líder dos comerciantes da praia de Tambaba.

As críticas aos resorts no município de Conde extraídas desta pesquisa são as mesmas que ocorreram em diversos destinos litorâneos nordestinos, isto é, a exclusão das comunidades locais dos benefícios do turismo, já que estes empreendimentos suscitam uma mão de obra mais qualificada (geralmente de fora da região); não movimenta o comércio local pelo fato do turista de resort ter todas suas necessidades satisfeitas dentro do próprio empreendimento. Com isso, ele não gera oportunidade de circulação de capital, provocando certo apartheid urbano, isto é, 
impedindo o contato com os turistas e a troca de experiências ou benefícios.

Para o líder da Colônia dos pescadores do município, o isolamento do resort é compreendido como um fator que gera exclusão social para essa categoria, incentivando o preconceito contra a comunidade: "Ficam olhando você como um marginal", justificou, afirmando ainda que estes empreendimentos "criam revolta, criam marginal". A comunidade pesqueira afirmou não vender seu produto para o resort construído explicando que os pescadores são desprestigiados pelo trade turístico que compram seus produtos geralmente fora, na capital paraibana. Vale salientar que o líder da associação pesqueira afirmou possuir um projeto artesanal de produtos derivados do peixe como pastéis, "coxinhas" e bolos de macaxeira. Todavia, não conseguiram nenhum tipo de parceria com os resorts ou meios de hospedagem, o que gera insatisfação por parte dessa comunidade:

\begin{abstract}
Nós fizemos uma degustação com nossos produtos, alguns vieram, mas não prestigiam, para nós é uma ofensa, pessoas de fora que vêm prestigiar, um trabalho todo artesanal. Quando provam, comem, levam pra casa, mas não ofertam aos hóspedes. É muito triste saber que tem um produto que não é valorizado (SECRETÁRIA DA ASSOCIAÇÃO DOS PESCADORES DE JACUMÃ, 2012).
\end{abstract}

Os agricultores da região também se sentem excluídos dos benefícios econômicos defendidos com a chegada desses empreendimentos, uma vez que não conseguem vender seus produtos para este tipo de empreendimento nem possuem nenhuma perspectiva de parceria. Um grupo de ciranda de uma dessas comunidades foi inclusive apresentado ao resort em funcionamento, mas nunca recebeu nenhum apoio ou espaço para apresentação. O líder do assentamento Dona Antônia mostrouse ainda preocupado com a crescente aquisição de terras pelos empresários de forma a prejudicar e inviabilizar a agricultura familiar: 
$|136|$

A produção do turismo no capitalismo contemporâneo:...

\begin{abstract}
A gente tem que ter cuidado pra eles (empresários) não comprarem tanto lugar (terra) porque se não a gente fica sem lugar (para a agricultura familiar). A gente tem medo desse pessoal que vem construindo, e comprando coisa muita, a gente fica meio alerta (LÍDER DOS AGRICULTORES DO ASSENTAMENTO DONA ANTÔNIA, 2012).
\end{abstract}

Para as líderes das comunidades quilombolas pesquisadas, a inserção destes resorts poderia ser positiva se gerassem de fato emprego e renda, afirmando que são destinados para as comunidades locais apenas os empregos de camareira, auxiliar de cozinha, de serviços, etc. A líder da comunidade do Gurugi afirmou conhecer três pessoas de sua comunidade que trabalham no resort em funcionamento. Na comunidade Ipiranga, a líder afirmou conhecer uma; todas trabalham nessas funções citadas anteriormente. Neste aspecto, a quantidade de empregos absorvidas pelas comunidades locais é pouco significativa considerando a oferta do trabalho decente defendida pela Organização Internacional do Trabalho que prevê condições dignas de sobrevivência a partir da remuneração desse emprego. Nas comunidades pesquisadas, o turismo vem como uma atividade complementar a renda oriunda da atividade econômica principal como agricultura e a pesca.

Por fim, para o líder da Associação dos Moradores e Amigos de Tabatinga, com objetivos ambientalistas e sociais de preservar o meio ambiente e trabalhar em prol dos interesses da comunidade, os resorts causam diversos impactos positivos e negativos, mas para que esses empreendimentos possam trazer desenvolvimento e benefícios locais é preciso "envolver a comunidade do entorno", o que ele acredita que não acontece.

Através de entrevistas semiestruturadas com os sete líderes comunitários foi possível perceber que, apesar da maioria dos líderes comunitários não ser contra os resorts, eles esperam uma contrapartida (econômica e social) que não está sendo realizada pelo empreendimento em funcionamento, e por isso, os impactos negativos citados foram bem maiores do que os impactos positivos. Entre os positivos foram citados: o aumento da capacidade 
hoteleira, o emprego, o aumento de divisas, o aumento do fluxo turístico, etc. Em relação aos impactos negativos foram citados a apropriação do espaço, a privatização da praia, a exclusão social, $\mathrm{o}$ preconceito com os nativos, o isolamento da comunidade pesqueira, a poluição, o desmatamento, entre outros.

\section{Considerações finais}

Desta forma, fica claro que a produção do turismo de massa está direcionada a lógica do capitalismo contemporâneo, na medida em que estimula o consumo, a imagem do produto e a subjetividade. Concomitantemente, a produção do turismo de massa apresenta ainda características do capitalismo moderno também presentes no modelo atual - como a acumulação de riqueza e prioridade do lucro em detrimento dos impactos socioambientais. Outras características deste modelo são a produção padronizada de souvenirs e destinos turísticos (através da urbanização) com características globais e a mercantilização das terras litorâneas, da cultura, entre outros.

No caso do mercado de resorts, esta realidade é ainda mais evidente quando se formam "bolhas" de consumo exclusivas para que os turistas consumam no local, tendo todas as suas necessidades satisfeitas pelo empreendimento, em detrimento do comércio local que não é aquecido e do frágil contato (ou ausência dele) com a realidade ou comunidades locais.

No município de Conde, o mercado que está se formando já aponta alguns impactos socioambientais nas comunidades locais, sendo os negativos os mais citados entre os líderes de comunidades locais. Dentre eles, prevalecem, sobretudo, os sócio-espaciais, que são menos referidos nos estudos de impacto ambiental, como a exclusão social, o preconceito e a apropriação do espaço.

Assim, a construção de espaços ilusórios de turismo do tipo resort, mesmo que promovam aumento do emprego e renda na região onde se insere, orienta-se para um desenvolvimento que reforça a hierarquia social através de espaços totalmente 
$|138|$

A produção do turismo no capitalismo contemporâneo:...

fechados, exclusivos aos turistas e desconectados do seu entorno, que se transformam em verdadeiros não-lugares. Estes espaços de concentração de riqueza e tecnologia, oriundos da modernização e urbanização turística, estão contribuindo com diversas transformações sociais, espaciais e ambientais, que privilegiam o grande capital.

Entretanto, numa visão pragmática do turismo, como este é o modelo predominante não só no Brasil, mas em todo o mundo, cabe ao poder público e as comunidades locais encontrar modelos alternativos de seinserirem na economia a partir da quebra de alguns paradigmas como a descentralização dos processos decisórios, buscando soluções viáveis e mais sustentáveis. Pois, conforme Oliveira (2007 p. 10) "não há como promover o desenvolvimento sem estimular o protagonismo local" que "implica, em alguns casos, em alterar as condições que possibilitaram a concentração do conhecimento, do poder e da riqueza".

\section{Bibliografia}

AUGÉ, M. El Viaje imposible. El turismo y sus imágenes. Barcelona: Editorial Gedisa, 1998a.

AUGÉ, M. Não-Lugares: introdução a uma antropologia da sobremodernidade. Portugal: Betrand Editora, 1998b.

BORGES, C. e LIMA, M. C. O turismo comunitário na zona costeira do Ceará: a experiência da Rede Tucum. Anais XVI Encontro Nacional de Geógrafos. Porto Alegre, 2010.

BRITO, V. Imagens e Representações da Ocupação Turística do Litoral Sul do Estado da Paraiba. Anais do V Encontro da ANPPAS - outubro de 2010 - Florianópolis - SC. Disponível em: <http://www.anppas.org.br/encontro5/cd/artigos/GT1570-534-20100903173217.pdf>. Acesso: 13/09/2012.

CARLOS, A. F. A. O Turismo e a Produção do Não Lugar. In: Turismo, Espaço, Paisagem e Cultura. Eduardo Yázigy, Ana 
Fani Alessandri Carlos e Rita de Cássia Ariza da Cruz (orgs.), 3aㅡ ed. São Paulo: Hucitec, 2002, p. 25 -37.

CORDEIRO, I; BENTO, E.; BRITTO, Carlos. Turismo e desenvolvimento sustentável: considerações sobre o modelo de resorts no litoral nordeste do Brasil. Caderno Virtual de Turismo. Rio de Janeiro, v. 11, n. 3, p. 355-369, dez. 2011.

COSTA, P. H; GODOY, P. R. O capitalismo contemporâneo e as mudanças no mundo do consumo. X Coloquio Internacional de Geocrítica. Barcelona, 2008.

CRUZ, R. de C. A. da. Introdução à geografia do turismo. S.Paulo: Rocca, 2001.

. Política de turismo e território. São Paulo: Contexto, 2002.

GASTAL, S. Turismo na Pós-modernidade: agregando imaginários. In: GASTAL, Susana; CASTROGIOVANNI, Antonio Carlos. Turismo na pós-modernidade: (des)inquietações. Porto Alegre: EDIPUCRS, 2003.

IANNI, O. Teorias da Globalização. Rio de Janeiro: Editora Civilização, 2002.

IGNARRA, L. Fundamentos do turismo. São Paulo: Pioneira Thomson Learning, 2003.

KRIPPENDORF, J. Sociologia do turismo: para uma nova compreensão do lazer e das viagens. São Paulo: Aleph, 2000.

LIMONAD, E. "Yes, nós temos bananas", praias, condomínios fechados, resorts e problemas sócio-ambientais. GEOgraphia, ano IX, $\mathrm{n}^{\mathrm{o}}$ 17, 2007. Disponível em: <http://www.uff.br/ geographia/ojs/index.php/geographia/article/view/215/207>. Acesso: 03/06/2011.

LOPES JÚNIOR, E. Urbanização turística, cultura e meio ambiente no nordeste brasileiro. IN: SERRANO, Célia M. Toledo; BRUHNS, Heloísa T. Viagens à natureza: turismo, cultura $e$ ambiente. São Paulo: Papirus, 1997. 
$\mid 140$ |

A produção do turismo no capitalismo contemporâneo:...

LUCHIARI, M. T. D. P. Urbanização turística: um novo nexo entre o lugar e o mundo. In: SERRANO, Célia; BRUHNS, Heloisa Turini; LUCHIARI, Maria Tereza D. P. (Orgs.) Olhares contemporâneos sobre o turismo. São Paulo: Papirus, 2000. p. 105-129.

MENDONÇA, R. Turismo ou meio ambiente: uma falsa oposição? In: Turismo: Impactos Socioambientais. São Paulo: Editora Hucitec, 1999.

OLIVEIRA, G. C. Desenvolvimento Local e Desenvolvimento Endógeno: redes de cooperação. 2007. Disponível em: www.fee.tche.br/4encontro-economia-gaucha/trabalhos/estudos-setoriaissessao53.

OURIQUES, H. R. A produção do turismo: fetichismo e dependência. Campinas, SP: Alínea, 2005.

PREFEITURA MUNICIPAL DE CONDE. Conde quer montar roteiro turístico Caminhos do Encanto. Disponível em: $<$ http:// www.condepb.com/site/index.php/turismo/37-eventos/194conde-que-montar-roteiro-turistico-caminhos-do-encanto>. Acesso: 10/09/2012.

RODRIGUES, A. A produção e o consumo do espaço para o turismo e a problemática ambiental. In: Turismo: Espaço, paisagem e cultura. Eduardo Yázigi, Ana Fani Alesssandri Carlos, Rita de Cássia Ariza da Cruz (Orgs). São Paulo: Hucitec, 1999.

SILVA, K. M; VIEIRA FILHO, N. Os resorts e seus impactos nas comunidades locais: estudo de caso do Águas do Treme Lake Resort no município de Inhaúma em Minas Gerais. Revista Observatório de Inovação e Turismo, vol. 4, no 3, 2009. Disponível em:<http://bibliotecadigital.fgv.br/ojs/index.php/oit/ article/viewFile/1594/1058>. Acesso: 15/07/2012.

THEOBALD, W. Turismo Global. São Paulo: Editora SENAC São Paulo, 2001.

YCARIM, M. B. O despertar do turismo: um olhar crítico sobre os nãolugares. São Paulo: Alpeph, 2001. 